\title{
Realization of voiceless stops and vowels in conversational French and Spanish
}

\author{
Francisco Torreira $^{\mathrm{a}, \mathrm{b}}$, Mirjam Ernestus ${ }^{\mathrm{a}, \mathrm{b}}$ \\ ${ }^{a}$ Center for Language Studies, Radboud Universiteit, Wundtlaan 1, 6525 XD, Nijmegen, \\ The Netherlands \\ ${ }^{b}$ Max Planck Institute for Psycholinguistics, Wundtlaan 1, 6525 XD, Nijmegen, The \\ Netherlands
}

\begin{abstract}
The present study compares the realization of intervocalic voiceless stops and vowels surrounded by voiceless stops in conversational Spanish and French. Our data reveal significant differences in how these segments are realized in each language. Spanish voiceless stops tend to have shorter stop closures, display incomplete closures more often, and exhibit more voicing than French voiceless stops. As for vowels, more cases of complete devoicing and greater degrees of partial devoicing were found in French than in Spanish. Moreover, all French vowel types exhibit significantly lower F1 values than their Spanish counterparts. These findings indicate that the extent of reduction that a segment type can undergo in conversational speech can vary significantly across languages. Language differences in coarticulatory strategies and "baseof-articulation" are discussed as possible causes of our observations.
\end{abstract}

\section{Introduction}

1.1. Phonetic reduction in conversational speech and purpose of this research

In conversational speech, segments often lack some or all of the acoustic cues that researchers are accustomed to finding in other, clearer, speech styles. For instance, intervocalic voiceless stops may lack their characteristic period of silence and burst (e.g. Lewis, 2001; Warner, 2005), while vowels may be produced with undershot formant frequencies (Koopmans-van Beinum, 1985; Moon and Lindblom, 1994, among others), and be partially or completely devoiced under the coarticulatory influence of neighboring voiceless consonants (e.g. Davidson, 2006; Torreira and Ernestus, 2010b). In extreme 
cases of reduction, segments may be acoustically absent (e.g. Browman and Goldstein, 1990; Johnson, 2004).

Reductions of this kind are often regarded as the consequence of the interaction between principles of economy of effort and universal articulatory and perceptual constraints (Lindblom, 1990). Under this hypothesis, reduction patterns should be largely the same in all languages. Common cross-linguistic coarticulatory patterns and recurrent diachronic lenitions (e.g. fronting of $/ \mathrm{k} /$ before front vowels, which lead to / $\mathrm{t} /$ in Romance, Slavic and Bantu languages; Recasens and Espinosa (2009)) support this view to a large extent. On the other hand, there are reasons to believe that at least some aspects of the reduction patterns present in connected speech are language-specific. For instance, it is now widely accepted that the strength and exact nature of coarticulatory processes often appears to differ among languages when closely examined (e.g. Öhman, 1966; Boyce, 1990; Manuel, 1990; Solé, 1995; Manuel, 1999; Beddor et al., 2002), and that the exact outcome of diachronic weakening processes is never predictable.

The present work directly compares the realization of intervocalic voiceless stops and vowels surrounded by voiceless stops in conversational Spanish and French in order to determine to what extent reduction patterns can differ between similar segmental sequences in two different languages. In order to assess reduction patterns within each language, we examine consonants and vowels in accented and unaccented syllables. According to manuals of Spanish and French pronunciation (e.g. Navarro Tomás, 1977; Tranel, 1987), the phonemes /p t k/ in these two languages should be pronounced similarly: as unaspirated voiceless stop consonants. However, previous studies carried out separately on French and Spanish raise the question of whether the speakers of these languages follow different production strategies when confronted with voiceless stops occurring between two vowels. Spanish voiceless stops in intervocalic position are frequently realized as voiced approximants in spontaneous speech (Lewis, 2001, and references therein), but to our knowledge no such tendency has been reported for French voiceless stops. On the other hand, unaccented high vowels in French can be extremely short and are often partially and sometimes even completely devoiced in the case of high vowels (Meunier et al., 2008; Torreira and Ernestus, 2010b), while vowel devoicing of this kind has not been reported for Spanish. These observations lead us to hypothesize that while French speakers privilege the articulation of voiceless stops and demonstrate greater vowel reduction, reduction in Spanish affects stops more than vowels. The present study addresses this hypothesis by di- 
rectly contrasting French and Spanish voiceless stops and vowels extracted from corpora of spontaneous speech.

A key aspect of the present study is that it uses corpora of conversational speech collected in a similar way for each language: the Nijmegen Corpus of Casual French (Torreira et al., 2010) and the Nijmegen Corpus of Casual Spanish (Torreira and Ernestus, 2010a). Importantly, these corpora contain casual, spontaneous conversations held by groups of acquainted speakers. We believe that data of this kind is needed to reveal the extent and nature of reduction phenomena in conversational speech.

In the following subsections, we introduce the main reduction patterns that we consider in this study: loss of total closures and the occurrence of voicing in intervocalic voiceless stops, and devoicing and formant undershoot for vowels.

\subsection{Reduction of voiceless stops}

According to standard descriptions of Spanish and French, voiceless stops in these languages should be realized similarly: with voiceless oral closures and no aspiration (e.g. Navarro Tomás, 1977; Tranel, 1987). Given the articulatory characteristics of these segments, in intervocalic position we can expect them to be weakened in two main ways. These two reduction patterns respectively involve the supraglottal and glottal components of the speech production system. First, at the supraglottal level, the stop closure can be temporally and spatially reduced, resulting in a stop with a short or an incomplete closure (e.g. Spanish físico /fisiko/ [fisizo] 'physical'). This kind of reduction has been reported to occur frequently in several Spanish dialects including Colombian and Northern Peninsular Spanish (Lewis, 2001) and Majorcan Spanish (Hualde et al., submitted). The present study further documents this phenomenon for spontaneous speech in Madrid Spanish, and examines the extent to which it occurs in standard French.

A second way in which intervocalic voiceless stops can be lenited involves voicing at the glottis. In intervocalic position, an optimal realization of $/ \mathrm{p} /$, $/ \mathrm{t} /$ or $/ \mathrm{k} /$ requires an abrupt cessation of glottal vibrations at the onset of the stop closure. However, due to the well-known tendency of contiguous speech gestures to overlap and blend with each other, or simply to reduce the size of the devoicing gesture (Browman and Goldstein, 1990), glottal vibrations from a preceding vowel may sometimes persist well into the stop closure, and even throughout its whole duration. Studies have shown that this reduction pattern is pervasive in several Spanish dialects. Lewis (2001), for Northern 
Peninsular and Colombian Spanish, and Hualde et al. (submitted) for Majorcan Spanish, found that phonologically voiceless intervocalic stops in these dialects are often significantly voiced, and that this tends to occur more often in conversational than in read speech, suggesting that the occurrence of voicing in intervocalic voiceless stops is a characteristic of hypoarticulated speech. The voicing of intervocalic voiceless stops has also been observed for the Spanish varieties spoken in Andalusia (Salvador, 1968), the province of Toledo (Torreblanca, 1976), Barcelona (Machuca-Ayuso, 1997), Cuba (Ruiz Hernández, 1984), Panama (Quilis and Graell, 1992), and the Canary Islands (Oftedal, 1985; Trujillo, 1970). The present study investigates the occurrence of this reduction phenomenon in Madrid Spanish, and examines the extent to which it occurs in French.

\subsection{Vowel reduction}

\subsubsection{Temporal and spectral reduction}

Vowels can be reduced in terms of duration and spectral characteristics (Lindblom, 1963; van Son and Pols, 1990, 1992; Moon and Lindblom, 1994, among many others). Reduction in duration is straightforward, but the relation between reduction and the spectral characteristics of vowels is less so. Traditionally, vowel reduction has been understood as a process of vowel centralization by which vowel types become less distinct from each other and more similar to a central schwa-like vowel (Stetson, 1951; Delattre, 1969). However, under the coarticulatory influence of consonants requiring a constricted vocal tract, as in our case, not only low vowels but also high vowels may be expected to become more closed in their articulation, leading not to centralization, but rather to a raising of the vowel space. For instance, Lindblom (1963) found that undershoot in Swedish /brb/, /drd/ and /grg/ sequences did not lead to higher F1 values, as predicted by the centralization hypothesis, but to lower F1 values instead.

\subsubsection{Vowel devoicing}

As mentioned above, we also aim to investigate the occurrence of vowel devoicing in French and Spanish vowels. European French is known for its use of vowel devoicing in phrase-final position as a prosodic and discourse marker (Fagyal and Moisset, 1999; Smith, 2003). Because many phrasefinal devoiced vowels in this language are long and sustained fricative noises preceded by voiced vocalic portions, rather than shortened or elided vowels, we cannot consider all cases of French phrase-final devoicing as instances of 
reduction. For this reason, phrase-final vowel devoicing is not considered in this study.

We will focus instead on phrase-medial devoicing (e.g. tu peux /ty pø/ [typø] 'you can'), another kind of devoicing reported to occur in European French (Martin, 2004; Meunier et al., 2008). Meunier et al. (2008) extracted short vowels $(<30 \mathrm{~ms}$ ) from a corpus of conversational French, and found complete devoicing in $20 \%$ of the high vowels examined, and in a few tokens of non-high vowels as well. In the vast majority of cases, the devoiced vowels were preceded, but not necessarily followed, by voiceless consonants. In a study based on the same French corpus used here, Torreira and Ernestus (2010b) further noted that devoicing is more likely the shorter the vowel, and provided some acoustic evidence of increased consonant-to-vowel coarticulation in syllables with fully devoiced vowels. These findings indicate that phrase-medial devoicing can be seen as a reduction process, since it appears to involve articulatory readjustments typical of such phenomena (e.g. shortening, increased coarticulation). In the present study, we compare the extent to which phrase-medial vowel devoicing occurs in Spanish and French vowels preceded and followed by voiceless stops.

\section{Method}

\subsection{Materials}

All of the speech data used in this study was extracted from the Nijmegen Corpus of Spontaneous Spanish (NCCSp; Torreira and Ernestus, 2010a) and the Nijmegen Corpus of Spontaneous French (NCCFr; Torreira et al., 2010). The corpora contain recordings of 52 Spanish speakers (27 female and 25 male) from Madrid and 46 French speakers (24 female and 22 male) from Central and Northern France, all engaged in conversations with friends. The NCCSp contains 20 conversations, while the NCCFr contains 23. Each of the recorded conversations had an approximate duration of 90 minutes. Except for two female speakers in the NCCFr, all speakers were university students in their late teens or twenties. The corpora were collected in sound-attenuated rooms in Madrid and Paris. The recording equipment consisted of an Edirol R-09 solid-state stereo recorder, Samson QV head-mounted unidirectional microphones and a stereo microphone preamplifier. The microphones were placed at an average distance of $5 \mathrm{~cm}$ from the left corner of the speakers' lips. The sampling rates used were $44.1 \mathrm{kHz}$ for the NCCSp and $48 \mathrm{kHz}$ for

the NCCFr. Importantly for our purposes, the NCCFr and NCCSp contain 
casual and spontaneous speech. Torreira et al. (2010) showed that the NCCFr contains significantly more informal words, swear words, hesitation sounds and other indicators of casualness than the ESTER corpus, a corpus of French radio broadcasts (Galliano et al., 2005). Since the NCCSp and the NCCFr were collected according to the same procedure, and contain recordings of speakers of the same socioeconomic background, we believe that the materials in the two corpora are of highly similar characteristics in terms of speech style.

Intervocalic voiceless stops and vowels between two voiceless stops were randomly extracted from the NCCSp and the NCCFr. Segments were always part of an open syllable in a content word, with stops always in onset position. We only analyzed sequences with vowel types shared by the Spanish and French vowel inventories (/a/, /e/,/i/,/o/ and /u/). For Spanish, therefore, all vowel types in its inventory were considered, while for French these were only a subset of the 14 to 16 vowel types generally recognized by linguists (e.g. Fougeron and Smith, 1993; Coveney, 2001; Fagyal et al., 2006). For Spanish, all lexically stressed syllables were considered as accented, since in this language lexically stressed syllables usually carry a pitch accent (except in rare cases of deaccentuation, as in parenthetical utterances; Prieto and Ortega-LLebaria, 2006). For French, only syllables carrying a primary accent were considered as accented. These syllables occurred at the end of prosodic units one level below the utterance level, corresponding to the Accentual Phrase in Jun and Fougeron (2002), the rhythmic unit in Di Cristo (1999) and the intonème mineur proposed by Rossi (1999). Syllables in non-phrasefinal position were considered as unaccented, excepting a few cases in which F0 signs of a prenuclear accent were found. These cases were excluded from analysis.

French is said to have mid-high $(/ \mathrm{e} /, / \mathrm{o} /)$ and mid-low vowels $(/ \varepsilon /, / \mathrm{\rho} /)$, but the existence of a phonological contrast between unaccented mid-high and mid-low vowels in this language is controversial, especially in open syllables, where more closed realizations are preferred according to the loi de position (see Nguyen and Fagyal, 2008, for a more detailed discussion). For this reason, in unaccented position we merged these vowel categories into single categories that we denote as /e/ and /o/. In accented syllables, on the other hand, we only considered mid-high vowels (/e/ and/o/), taking as a reference Le Petit Robert, a widely-used dictionary of standard French.

The dataset contains a total of 1298 stops and 727 vowels for Spanish, and 856 stops and 497 vowels for French. Speakers contributed from two to 58 tokens, with an average contribution of 21.9 tokens and a standard deviation 
Table 1: Examples of words and word sequences including target voiceless stops and vowels (underlined) extracted from the NCCSp and NCCFr. Square brackets represent accentual phrase boundaries in the examples of French accented vowels.

Spanish

\begin{tabular}{|c|c|}
\hline Unaccented & Accented \\
\hline diputado /diputado/ 'deputy' & ataca /ataka/ 'attacks' \\
\hline protocolo / protokolo/ 'protocol' & que lo quites / kelokites/ 'that you remove it' \\
\hline lo poquito /lopokito/ 'the little bit' & un poquito /unpokito/'a little bit' \\
\hline \multicolumn{2}{|l|}{ French } \\
\hline Unaccented & Accented \\
\hline va couper /vakupe/ 'going to cut' & va couper ta /vakupe]ta/ 'going to cut your' \\
\hline $\begin{array}{l}\text { du côté /dykote/ 'on the side' } \\
\text { critiquer /kRitike/ 'criticize' }\end{array}$ & $\begin{array}{l}\text { au cas par cas tu /okapaRka]ty/ 'case by case } \\
\text { critiquer ta / kRitike]ta/ "criticize your' }\end{array}$ \\
\hline
\end{tabular}

Table 2: Numbers of unaccented and accented voiceless stop consonants in the dataset for each language.

\begin{tabular}{|c|c|c|c|c|c|c|}
\hline & \multicolumn{3}{|c|}{ Unaccented } & \multicolumn{3}{|c|}{ Accented } \\
\hline & $/ \mathrm{p} /$ & $/ \mathrm{t} /$ & $/ \mathrm{k} /$ & $/ \mathrm{p} /$ & $/ \mathrm{t} /$ & $/ \mathrm{k} /$ \\
\hline French & 136 & 63 & 175 & 186 & 208 & 88 \\
\hline Spanish & 267 & 141 & 163 & 163 & 375 & 189 \\
\hline
\end{tabular}

of 12.7. Table 1 presents examples of unaccented and accented voiceless stops and vowels in our dataset. Tables 2 and 3 show the numbers of segments in the dataset broken down by accent, type, and language. Remember that all analyzed voiceless stops are in onset position and take the accent value of the following vowel.

\subsection{Measurements}

In order to investigate the realization of voiceless stops and vowels in French and Spanish, we measured stop closure, vowel and voicing durations, intensity velocity maxima during the consonant-to-vowel (CV) transitions, 
Table 3: Numbers of unaccented and accented vowels in the dataset for each language.

\begin{tabular}{lcccccccccc} 
& \multicolumn{4}{c}{ Unaccented } & \multicolumn{4}{c}{ Accented } \\
\hline & $/ \mathrm{a} /$ & $/ \mathrm{e} /$ & $/ \mathrm{i} /$ & $/ \mathrm{o} /$ & $/ \mathrm{u} /$ & /a/ & /e/ & /i & $/ \mathrm{o} /$ & /u/ \\
\hline French & 129 & 32 & 55 & 106 & 52 & 26 & 39 & 21 & 15 & 22 \\
Spanish & 152 & 120 & 91 & 158 & 50 & 19 & 26 & 34 & 42 & 35 \\
\hline
\end{tabular}

and formant frequencies in the vowels of interest. The durations of the target stop closures and vowels were measured manually. Following Turk et al. (2006), acoustic segment durations were defined on the basis of the onsets and releases of consonantal constrictions rather than on voicing. Therefore, consonant duration included only the stop closure interval, while vowel duration included the interval extending from an oral release to the upcoming oral closure. Stop closures were annotated as being incomplete if uninterrupted acoustic energy was present in the spectrograms above the frequency band characteristic of voicing between the vowels flanking the stop. No duration values were assigned to stops with an incomplete closure nor to their contiguous vowels, since the boundaries between these segments cannot be determined on the basis of robust acoustic landmarks.

The presence of voicing within the target stops (intervocalic voicing) and vowels was identified automatically with the pitch detection function provided in Praat set to default parameters except for a time step of $2.5 \mathrm{~ms}$ (Boersma, 1993; Boersma and Weenink, 2009). Voiceless vowel duration (VVD) was recorded as the interval from the stop release up to the first pitch point detected in the vowel, or, in the case of completely devoiced vowels, up to the following stop closure. Figures 1 to 3 illustrate our temporal measures.

As an additional measure of consonantal strength, we measured the intensity velocity maxima in CV transitions. Stops with full closures and salient bursts should be characterized by abrupt rises in intensity and should therefore yield highly positive values of this measure, while weakened stops should exhibit values close to zero. In order to factor out most of the effects of voicing (fundamental frequency and first few harmonics), the signals were first high-passed filtered at $1 \mathrm{kHz}$. Intensity contours were calculated using a 30 ms window and a time step of $8 \mathrm{~ms}$. We then identified the points of minimum intensity in the stop closure and of maximum intensity in the following 
Figure 1: Illustration of temporal measures featuring the syllable /pa/ in the French word paquet 'packet'. IV: intervocalic voicing; VVD: voiceless vowel duration; CD: closure duration; VD: vowel duration.

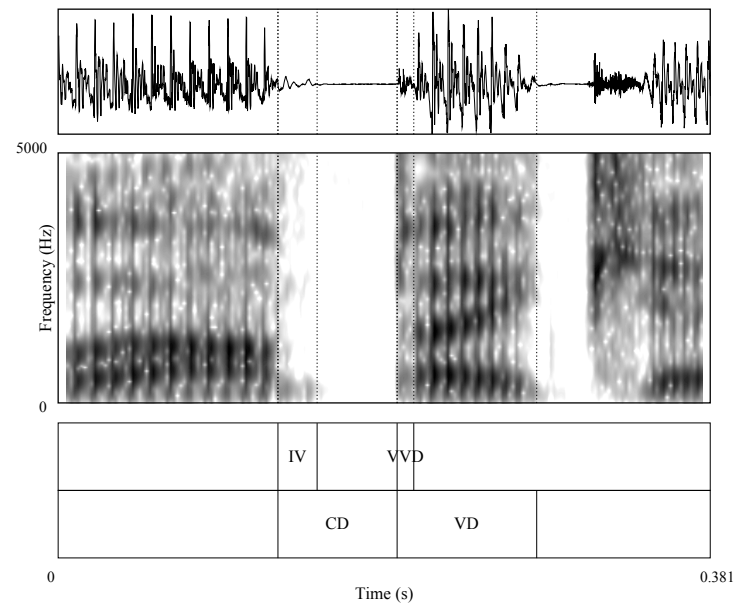

Figure 2: Illustration of temporal measures featuring the syllable /to/ in the Spanish word autopista 'highway'. IV: intervocalic voicing; CD: closure duration; VD: vowel duration.
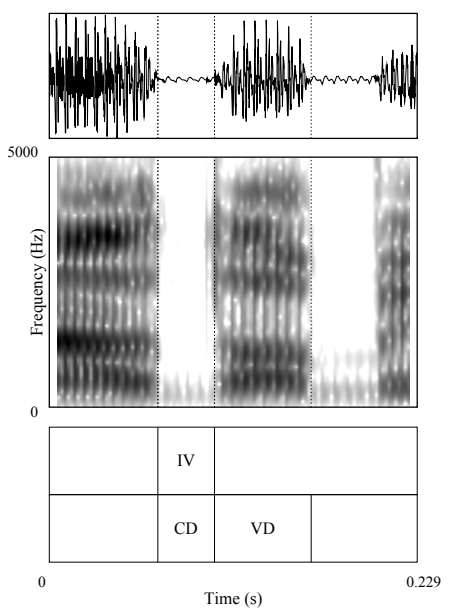
Figure 3: Illustration of temporal measures featuring the syllable /pi/ in the French word capitale 'capital'. IV: intervocalic voicing; VVD: voiceless vowel duration; CD: closure duration; VD: vowel duration.

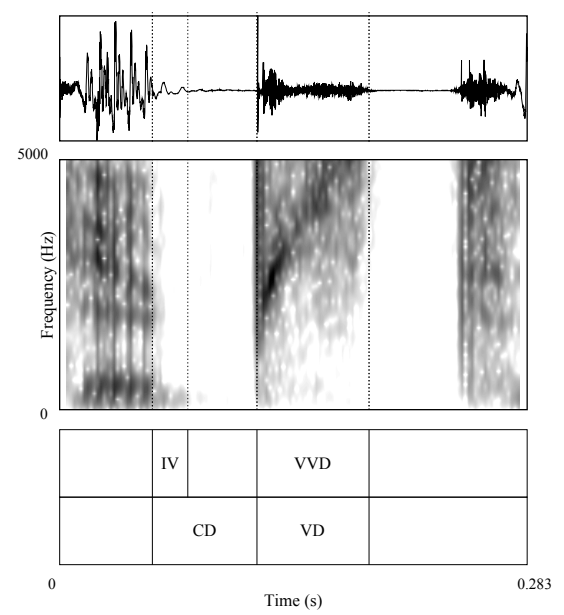

vowel, and calculated intensity velocity maxima from the first derivative of the intensity curve between these two points. Derivatives were obtained by smoothing the contours via cubic interpolation and by calculating local differences in intensity using a time step of $1 \mathrm{~ms}$.

Formant frequencies were estimated through the target vowels with the Burg method as implemented in Praat (with default settings except for the ceiling parameter, see below). Formant measurements were taken at the point of maximum F1 within the vowel, which usually occurred around its midpoint. In order to reduce the number of formant tracking errors, we adjusted the ceiling frequency of the formant tracker for each vowel type and gender following median optimal values provided in Escudero et al. (2009) for Portuguese vowels. Applying these ceilings resulted in a clear improvement in formant detection, as indicated by a drastic reduction in unlikely formant values (e.g. F2 values with typical F1 values). Inspection of the remaining unlikely values revealed that they mostly belonged to extremely short and sometimes devoiced vowels with either very weak or absent formants (F1 in particular). These cases (143 out of 1224) were excluded from the analysis of formant values. Since there are no reasons to suspect that French and 
Spanish speakers systematically differ in vocal tract length, and given the large number of speakers as well as the similar number of men and women in our dataset, we decided to use raw F1 values rather than to apply any specific procedure of formant normalization.

The direction of the effect of coarticulation on the F2 and F3 of a specific vowel crucially depends on its particular segmental context (Lindblom, 1963). For instance, central vowels can be expected to show higher F2 in the context of segments with an anterior place of articulation, and lower F2 in the context of segments with a posterior place of articulation. Since our unbalanced dataset does not allow us to compute reliable statistical estimates for each combination of segments under examination, we exclusively focus on F1 when assessing the degree of coarticulation between target vowels and the surrounding stop consonants. In this case, we can make the general prediction that more reduced and coarticulated vowels will display lower F1 values regardless of their segmental context (see section 1.3.1).

A check was performed in order to assess the reliability of the measurements and annotations which had been done manually by the first author (i.e. closure and vowel durations, and the presence of a complete closure). One hundred and fifty stops and vowels (75 stops and vowels for each language) were randomly extracted from the dataset, and independently reanalyzed by an assistant unaware of the purposes of our study. No major disagreement was found between our measurements and those of the independent transcriber $(93.5 \%$ of closure duration measurements and $87.7 \%$ of vowel duration measurements differed by $10 \mathrm{~ms}$ or less between the two annotators, and the annotation of complete and incomplete closures coincided in $93.3 \%$ of the cases).

\section{Analysis and results}

\subsection{Analysis}

In this section we analyze the presence of incomplete closures, intensity velocity maxima in CV transitions, closure duration, and intervocalic voicing for voiceless stops, and vowel duration, voiceless vowel duration, and F1 values for vowels. Apart from language (Spanish, French), consonant type (/p/, $/ \mathrm{t} /, / \mathrm{k} /)$ and vowel type $(/ \mathrm{a} /, / \mathrm{e} /, / \mathrm{i} /, / \mathrm{o} /, / \mathrm{u} /)$, we consider accent (accented vs. unaccented) as predictors. Position in the word (word-initial vs. word-medial) was included in the analysis of consonants in order to control for variance, since this factor has been reported to condition the strength 
with which consonants are articulated (see Keating, 2006, and references therein). In the analysis of incomplete closures, we also consider the height of the surrounding vowels, since incomplete closures can be expected to occur more often between open vowels (/a/) than between closed vowels (/i/ and $/ \mathrm{u} /$ ) for coarticulatory reasons.

For all analyses, we use mixed-effects linear regression with contrast coding as implemented in the lmer function in R (Bates and Sarkar, 2006). For the presence of incomplete closures, a binary dependent variable, we use logistic mixed-effects linear regression. In all analyses, speaker is considered as a random factor. Word type was not included in the analyses as a random factor, since many of the used word types had only one or two tokens in the dataset.

A regression table is provided for each analysis (except for the analyses of F1 values, see below). Each table contains an intercept corresponding to a baseline combination of levels indicated in the caption (e.g. French unaccented $/ \mathrm{k} /$ ) and additional terms corresponding to levels not represented by the intercept (e.g. /p/, Spanish, accented). The regression coefficients for each term $(\beta)$ indicate deviations from the intercept. These coefficients are in $\mathrm{ms}$ for temporal dependent variables, in $\mathrm{dB} / \mathrm{s}$ for maximum intensity velocities, and in $\mathrm{Hz}$ for the models predicting F1. Only statistically significant predictors (with all their levels, whether significant or not) are kept in the models and shown in the tables. For categorical predictors with more than two levels, pairwise comparisons not involving the baseline level were done by rerunning the model with new baselines. These comparisons are not provided in the tables, but are mentioned in the text whenever they are statistically significant.

\subsection{Voiceless stops}

In the analysis of voiceless stops, we first investigate the likelihood of incomplete closures, and intensity velocity maxima in the CV transitions, then closure duration for those consonants with a complete closure, and finally the occurrence of intervocalic voicing.

\subsubsection{Incomplete closures}

In order to quantify differences in the likelihood of incomplete closures in Spanish and French voiceless stops, we fitted a logistic regression model with closure degree as response (complete vs. incomplete), speaker as random factor, and language (Spanish vs. French), stop type (/p/ vs. /t/ vs. /k/), 
Table 4: Regression coefficients with $z$ and $p$ values for the model predicting the likelihood of incomplete closures. The intercept corresponds to French, unaccented, word-initial /k/ consonants.

\begin{tabular}{llrrl}
\hline Term & Level & $\beta$ & $z$ & $p$ \\
\hline Intercept & & -3.36 & & \\
Language & Spanish & 3.17 & 6.77 & $<.0001$ \\
Stop type & $/ \mathrm{p} /$ & -0.96 & -2.32 & $<.05$ \\
Stop type & $/ \mathrm{t} /$ & -0.79 & -1.89 & \\
Accent & accented & -0.69 & -4.37 & $<.0001$ \\
Position & medial & 1.56 & 3.61 & $<.0005$ \\
Language * Position & Spanish, medial & -1.12 & -2.47 & $<.05$ \\
Language * Stop type & Spanish, /p/ & -0.47 & -1.04 & \\
Language * Stop type & Spanish, /t/ & -0.98 & -2.14 & $<.05$ \\
\hline
\end{tabular}

accent (unaccented vs. accented), position in the word (initial vs. medial), previous vowel height, and following vowel height (high vs. mid vs. low) as fixed factors. Table 4 shows the regression results for this model.

Spanish tended to have significantly more incomplete closures than French $(25.5 \%$ vs. $5.4 \% ; p<.0001)$. This result confirms our expectation that Spanish voiceless stops are more likely to have reduced closures than French voiceless stops (see Section 1.1). This language effect interacted with consonant type in that the difference between the two languages was not so marked for consonant $/ \mathrm{t} /(15.1 \%$ vs. $5 \%$; $p<.05)$. Language also interacted with position in the word: French tended to have more incomplete closures in wordmedial than in word-initial position $(p<.0005)$, but no such tendency was observed for Spanish (in this language incomplete closure occurred equally often in word-initial and word-medial positions). Finally, in both languages, incomplete closures were less common for consonant $/ \mathrm{p} /$ than for consonant $/ \mathrm{k} /(p<.05)$, and in accented than in unaccented syllables $(p<.0001)$.

\subsubsection{Maximum intensity velocity in $C V$ transition}

We then investigated language differences in maximum intensity velocity during the transition of the voiceless stop into the following vowel. Reduced stops should be characterized by values close to zero (i.e. by very gradual rises in intensity during the $\mathrm{CV}$ transition), while stops with clear closures 
Figure 4: Density plots of maximum intensity velocity in CV transition for French (black) and Spanish (grey) stop consonants.
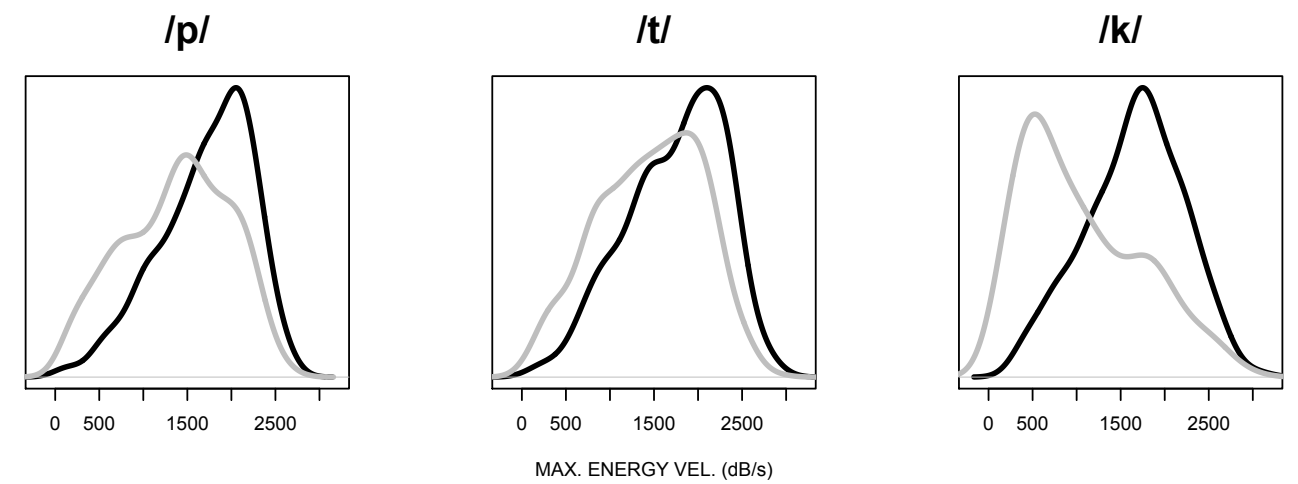

and bursts should yield highly positive values. Figure 4 shows kernel density plots $^{1}$ of this measure for each stop type and language. It can be seen that Spanish stops tend to have lower values and therefore less abrupt intensity changes in their CV transitions than French stops. Most noticeably, a majority of the Spanish instances of $/ \mathrm{k} /$ in our data appear to be particularly weak relative to their French counterparts.

Importantly, it can also be seen from these plots that, even in the case of $/ \mathrm{k} /$, a significant portion of Spanish stops had values similar to those most common of French stops. Thus, our data indicate that Spanißß3?sh stops are not simply more reduced than French stops in general, but rather show more variability than French stops in that they become weakened significantly more often.

\footnotetext{
${ }^{1}$ Kernel density plots display the estimated probability density function (y-axis) of a continuous random variable ( $\mathrm{x}$-axis), and have a purpose similar to that of histograms. However, whereas histograms group observations into a discrete number of bins, kernel density plots provide a continuous estimate of the distribution of a variable. The kernel density plots shown here were computed using the density function in $\mathrm{R}$ with default parameters. Note that the area under each curve integrates to 1 . For further details, see the R manual (R Development Core Team, 2008) and Sarkar (2008).
} 
In order to examine whether these differences in our intensity velocity measures were statistically significant and not caused by effects of accent and position in the word, we fitted a regression model with maximum intensity velocity as response, speaker as random factor, and language (Spanish vs. French), stop type (/p/ vs. /t/ vs. /k/), accent (unaccented vs. accented) and position in the word (initial vs. medial) as fixed factors.

The resulting model is given in Table 5. A main effect of language and an interaction between language and stop type confirmed the impression given by Figure 4 that Spanish and French differ in maximum intensity velocity and that this difference is bigger for $/ \mathrm{k} /$ than for the other two consonant types $^{2}$. This is an agreement with the results of the previous subsection, which indicated that the two languages differed especially in the realization of $/ \mathrm{k} /$ closures. Both accent and position in the word had the expected effects on maximum intensity velocity: accented and word-initial stops tended to have more abrupt intensity rises than unaccented and word-medial stops (respectively $<.0001$ and $<.005)$.

\subsubsection{Closure duration}

In order to test for language differences in closure duration, we ran a linear regression model with closure duration as response, speaker as random factor, and language, stop type, accent, and position in the word as fixed factors. Only consonants with a full closure $(n=1734)$ were included in this analysis.

Table 6 shows the results of this model. Spanish tended to have shorter closures than French $(p<.0001)$. Spanish stops are not only more reduced than French stops in constriction degree, as shown in the two previous subsections, but also in the temporal dimension. As in the analysis of incomplete closures (section 3.2.1), an interaction was found between language and position in the word. Consonants tended to be shorter in word-medial than in word-initial position in French $(p<.0001)$, but not in Spanish. We also found effects of stop type and accent affecting both languages in the same

\footnotetext{
${ }^{2}$ The editors note that this difference might be due to an unbalanced vocalic context in the datasets of the two languages. For instance, if / ku/ were more frequent, and /ki/ less frequent, in the Spanish than in the French dataset, the observed difference might be due to the sample rather than to language-specific reduction patterns. Inspection of the data showed that in fact, $/ \mathrm{ku} /$ was more frequent, and /ki/ less frequent, in the French than in the Spanish dataset. We therefore do not think that an unbalanced sample is the cause of the observed difference between the two languages
} 
Table 5: Regression coefficients with $t$ and $p$ values for the model predicting intensity velocity maxima in CV transitions. The intercept corresponds to French, unaccented, word-initial / k/ consonants.

\begin{tabular}{llrrl}
\hline Term & Level & $\beta$ & $t$ & $p$ \\
\hline Intercept & & 50.6 & & \\
Language & Spanish & -590.13 & -8.43 & $<.0001$ \\
Stop type & $/ \mathrm{p} /$ & 63.96 & 1.24 & \\
Stop type & $/ \mathrm{t} /$ & 51.97 & 0.9 & \\
Accent & accented & 176.1 & 4.9 & $<.0001$ \\
Position & medial & -121.81 & -3.21 & $<.005$ \\
Language * Stop type & Spanish, /p/ & 262.66 & 3.84 & $<.0005$ \\
Language * Stop type & Spanish, /t/ & 329.96 & 4.82 & $<.0001$ \\
\hline
\end{tabular}

Table 6: Regression coefficients with $t$ and $p$ values for the model predicting closure duration. The intercept corresponds to French, unaccented, word-initial /k/ consonants.

\begin{tabular}{llrrl}
\hline Term & Level & $\beta$ & $t$ & $p$ \\
\hline Intercept & & 50.6 & & \\
Language & Spanish & -11.62 & -6.07 & $<.0001$ \\
Stop type & $/ \mathrm{p} /$ & 14.26 & 14.43 & $<.0001$ \\
Stop type & $/ \mathrm{t} /$ & 5.90 & 5.85 & $<.0001$ \\
Accent & accented & 5.08 & 5.56 & $<.0001$ \\
Position & medial & -7.15 & -5.31 & $<.0001$ \\
Language * Position & Spanish, medial & 7.19 & 4.43 & $<.0001$ \\
\hline
\end{tabular}


Table 7: Regression coefficients with $t$ and $p$ values for the model predicting intervocalic voicing duration. The intercept corresponds to French, unaccented, word-initial /k/ consonants.

\begin{tabular}{llrll}
\hline Term & Level & $\beta$ & $t$ & $p$ \\
\hline Intercept & & 10.96 & & \\
Closure duration & & 0.19 & 9.18 & $<.0001$ \\
Language & Spanish & 2.11 & 1.22 & \\
Stop type & $/ \mathrm{p} /$ & 3.9 & 3.09 & $<.005$ \\
Stop type & $/ \mathrm{t} /$ & -2.05 & -1.6 & \\
Language * Stop type & Spanish, /p/ & 8.69 & 4.88 & $<.0001$ \\
Language * Stop type & Spanish, /t/ & 7.7 & 4.32 & $<.0001$ \\
\hline
\end{tabular}

degree. Stop closures were longer for $/ \mathrm{t} /$ than for $/ \mathrm{k} /(p<.0001)$, as well as for $/ \mathrm{p} /$ than for $/ \mathrm{t} /(\beta=8.35, t=9.41, p<.0001)$. Finally, accented stops had longer closures than unaccented stops in both languages $(p<.0001)$.

\subsubsection{Intervocalic voicing}

We then examined whether and how the interval of voicing during the realization of phonologically voiceless stops differed between French and Spanish. A first look at the data showed that intervocalic voicing was more pervasive in Spanish than in French voiceless stops. Closures were completely voiced in $32.7 \%$ of the Spanish stops, and only in $8.5 \%$ of the French stops. Moreover, in Spanish, $61.8 \%$ of stop closures were voiced for at least $50 \%$ of their duration or more, while in French this was the case only for $31.8 \%$ of the stop closures.

We then investigated in more detail which variables predict the duration of intervocalic voicing. Since intervocalic voicing duration could not be measured for incomplete closures, we limited our statistical analysis to stops with complete closures. We focused on duration rather than on the proportion of intervocalic voicing within the closure, since the latter did not have a normal distribution. We considered closure duration as a covariate, and language, stop type, accent, and position in the word as potential predictors. Speaker was included as a random factor. Table 7 shows the results of this model. Spanish tended to have longer durations of intervocalic voicing than French, but only for consonants $/ \mathrm{p} /$ and $/ \mathrm{t} /$, as shown by the absence of a main 
effect and the statistical significance of the two interaction terms $(p<.0001$ in both cases). In both languages, intervocalic voicing was longer for $/ \mathrm{p} /$ than for $/ \mathrm{k} /(p<.005)$ and $/ \mathrm{t} /(\beta=5.96, t=4.82, p<.0001)$, presumably due to the aerodynamic characteristics of bilabial stops (i.e. longer build-ups of intraoral pressure; Ohala and Riordan, 1979).

We finally counted how many incomplete closures were voiceless at some point in their realization. For French, we inspected all stops with an incomplete closure in the dataset, while for Spanish we examined a random sample of 200. Twenty-five out of the 45 incomplete closures (55.5\%) were voiceless at some point for French, while only two cases (1\%) were not voiced throughout for Spanish. Taken together, these results show that the occurrence of voicing is significantly more common in Spanish than in French intervocalic voiceless stops.

\subsection{Vowels}

As explained in the Method section, the interval that we marked as a vowel includes the stretch of signal between two stop closures, corresponding to the interval during which the vocal tract was not completely constricted. The stop release and following voiceless stretch of signal preceding the onset of voicing are therefore included in this interval. We examine language differences in vowel duration, in the occurrence and duration of voicelessness within this vowel interval, and finally in F1.

\subsubsection{Duration}

In order to investigate language differences in vowel duration, we fitted a regression model with vowel duration as response, speaker as random factor, and language, vowel type, and accent as fixed predictors. Since the vowel interval contained the release of the preceding stop, the identity of the preceding consonant was also included in the model as a predictor. The results of this model are shown in Table 8. In general, Spanish vowels tended to be shorter than French vowels $(p<.0001)$, especially $/$ i/ vowels $(p<.005)$. As expected, accented vowels tended to be longer than unaccented vowels for both languages $(p<.0001)$, but this difference was more pronounced in French than in Spanish, as shown by the significant interaction term in Table $8(p<.0001)$. Finally, vowels tended to be shorter if preceded by consonant $/ \mathrm{p} /$ in French $(p<.005)$, but not in Spanish. These findings indicate that Spanish vowels tend to be slightly shorter than French vowels. At the 
Table 8: Regression coefficients with $t$ and $p$ values for the model predicting vowel duration. The intercept corresponds to French, unaccented /a/ vowels preceded by a /k/ consonant.

\begin{tabular}{|c|c|c|c|c|}
\hline Term & Level & $\beta$ & $t$ & $p$ \\
\hline Intercept & & 92.46 & & \\
\hline Language & Spanish & -17.56 & -5.02 & $<.0001$ \\
\hline Vowel type & $/ \mathrm{e} /$ & -7.38 & -2.47 & $<.05$ \\
\hline Vowel type & /i/ & -0.79 & -0.26 & \\
\hline Vowel type & /o/ & -6.17 & -2.53 & $<.05$ \\
\hline Vowel type & $/ \mathrm{u} /$ & -11.97 & -4.18 & $<.0001$ \\
\hline Accent & accented & 28.61 & 12.81 & $<.0001$ \\
\hline Stop type & $/ \mathrm{p} /$ & -9.6 & -4.37 & $<.0001$ \\
\hline Stop type & $/ \mathrm{t} /$ & -1.98 & -0.79 & \\
\hline Language ${ }^{*}$ Vowel type & Spanish, /e/ & -5.98 & -1.46 & \\
\hline Language ${ }^{*}$ Vowel type & Spanish, /i/ & -13.55 & -3.18 & $<.005$ \\
\hline Language ${ }^{*}$ Vowel type & Spanish, /o/ & -2.19 & -0.61 & \\
\hline Language ${ }^{*}$ Vowel type & Spanish, /u/ & 3.21 & 0.75 & \\
\hline Language $*$ Accent & Spanish, accented & -18.46 & -6.07 & $<.0001$ \\
\hline Language $*$ Stop type & Spanish, /p/ & 10.89 & 3.29 & $<.005$ \\
\hline Language $*$ Stop type & Spanish, /t/ & 1.87 & 0.52 & \\
\hline
\end{tabular}


Table 9: Regression coefficients with $t$ and $p$ values for the model predicting voiceless vowel duration. The intercept corresponds to French /a/ vowels preceded by a /k/ consonant.

\begin{tabular}{llrrl}
\hline Term & Level & $\beta$ & $t$ & $p$ \\
\hline Intercept & & 8.34 & & \\
Vowel duration & & 0.19 & 7.83 & $<.0001$ \\
Language & Spanish & -5.43 & -2.78 & $<.001$ \\
Stop type & /p/ & -4.29 & -3.72 & $<.0005$ \\
Stop type & $/ \mathrm{t} /$ & 0.73 & 0.58 & \\
Vowel type & /e/ & -0.2 & -0.1 & \\
Vowel type & $/ \mathrm{i} /$ & 24.13 & 10.41 & $<.0001$ \\
Vowel type & /o/ & 0.04 & 0.02 & \\
Vowel type & /u/ & 11.49 & 5.68 & $<.0001$ \\
Language * Vowel type & Spanish, /e/ & -0.93 & -0.33 & \\
Language * Vowel type & Spanish, /i/ & -23.5 & -7.51 & $<.0001$ \\
Language * Vowel type & Spanish, /o/ & 0.3 & 0.12 & \\
Language * Vowel type & Spanish, /u/ & -11.28 & -3.80 & $<.0005$ \\
\hline
\end{tabular}

temporal level, then, our initial expectation that French would exhibit more vowel reduction than Spanish is not borne out by the data.

\subsubsection{Voicing}

We then investigated whether the extent of voicelessness within the interval marked as a vowel (which included the consonantal release) differed between Spanish and French. We found that in French, 24 out of 451 vowels were completely devoiced. Closer inspection revealed that the majority of these vowels were high unaccented vowels $(n=21,19.6 \%$ of high unaccented vowels in the French dataset). In Spanish, on the other hand, we found only one case of complete devoicing.

Differences in the extent of partial devoicing could not be investigated with the proportion of voicelessness within the vowel interval, since this measure did not present a normal distribution. Alternatively, we fitted a regression model with voiceless vowel duration (the absolute duration of the voiceless stretch within the vowel interval) as response, speaker as random factor, vowel duration as a covariate, and language, vowel type, preceding 
stop type, and accent as predictors (c.f. the analysis of intervocalic voicing in section 3.2.4). Importantly, the use of vowel duration as a covariate allows us to test for relative differences in the duration of voicelessness within the vowel interval. The results of this model are shown in Table 9. In accordance with the cross-linguistic tendency for $/ \mathrm{k} /$ to have longer Voice Onset Time (VOT) than /p/ and /t/ (Cho and Ladefoged, 1999), voiceless vowel duration, a measure related to VOT, was longer for consonant $/ \mathrm{k} /$ than for consonant $/ \mathrm{p} /(p<.0005)$. More importantly, there was a main effect of language and an interaction between language and vowel type. French had longer voiceless vowel durations than Spanish, especially for the high vowels /i/ and /u/ (/i/: $p<.0001 ; / \mathrm{u} /: p<.0005)$.

Together, the counts of cases of complete devoicing and the analysis of voiceless vowel duration indicate that vowel devoicing occurs almost exclusively in high French vowels.

\subsubsection{Formant values}

We finally investigated whether French and Spanish vowels surrounded by voiceless stops differed in F1. A regression model was fitted with F1 as the response variable, language, speaker gender, accent, and vowel type as predictors, and speaker as a random factor. A four-way interaction between language, accent, vowel type, and gender was found for $\mathrm{F} 1(F(4,1041)=$ $2.64, p<.05)$. In order to interpret this interaction, we split the dataset by vowel type and fitted models with language, accent, and gender as predictors. Instead of providing the details of these five models in separate tables, we summarize our main findings. First, all vowel types had statistically higher F1 in Spanish than in French $(/ \mathrm{a} /: \beta=89.32, t=4.26, p<.0001 ; \mathrm{e} / \mathrm{:}$ $\beta=111.36, t=10.03, p<.0001 ; / \mathrm{i} /: \beta=108.16, t=9.76, p<.0001 ; / \mathrm{o} / \mathrm{:}$ $\beta=147.89, t=16.88, p<.0001 ; \mathrm{u} /: \beta=121.19, t=9.79, p<.0001)$. This trend can be seen clearly in Figures 5 and 6 , which shows boxplots of F1 values for females and males separately.

Second, accented vowels tended to have higher F1 values than unaccented vowels both in French and Spanish, but this effect was statistically significant only for the following combinations of language, vowel and gender: /e/ and /o/ vowels for both genders and languages $(/ \mathrm{e} / \mathrm{:} \quad \beta=32, t=3.64, p<$ $.0005 ; / \mathrm{o} /: \beta=147.89, t=16.88, p<.0001), / \mathrm{a} /$ vowels in French male and female speakers, and for Spanish females (main effect of accent: $\beta=$ $53.08, t=2.45, p<.05$; three-way interaction of accent, accent and gender: $\beta=-136.50, t=-2.93, p<.005$ ), and French high vowels (main effect of 
accent for $/ \mathrm{i} /: \quad \beta=54.57, t=4.1, p<.0001$; interaction of language and accent for $/ \mathrm{i} /: \beta=-61.61, t=-3.78, p<.0001$; main effect of accent for $/ \mathrm{u} /: \quad \beta=38.59, t=2.87, p<.01$; interaction of language and accent for $/ \mathrm{u} /: \beta=-34.63, t=-2.12, p<.05)$. It is worth noting that the differences observed between Spanish and French are not merely statistically significant, but actually of a considerable size. For instance, the boxplots ${ }^{3}$ in Figures 5 and 6 show that numerous tokens of French /a/ and /e/ vowels had F1 values respectively comparable to those of many Spanish /e/ and /i/ vowels.

In summary, we found that all French vowels had significantly lower F1 values than Spanish vowels, suggesting that they tend to be articulated with a more constricted vocal tract than their Spanish counterparts. Accent showed a consistently similar effect in both languages whenever it reached statistical significance.

Figure 5: Boxplots of F1 values for French (white) and Spanish (grey) vowels produced by female speakers.

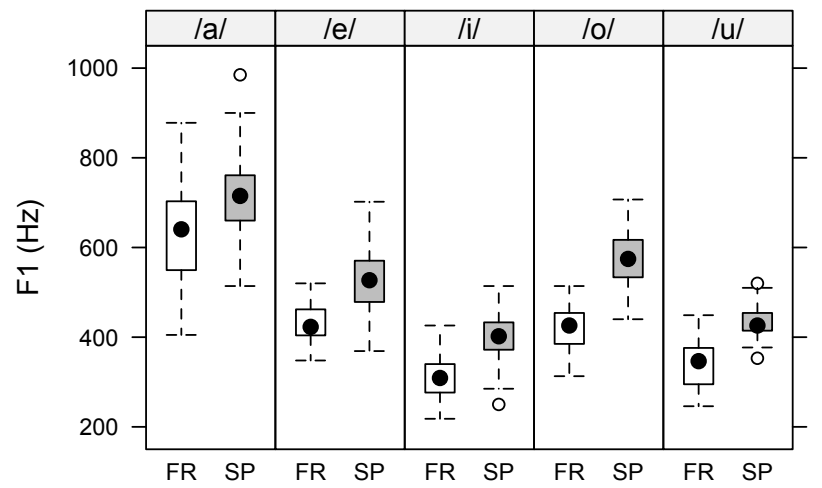

\footnotetext{
${ }^{3}$ The rectangle in a boxplot contains the middle $50 \%$ of the data points (the interquartile range, IQR). The whiskers include data points beyond this range, extending up to a length of 1.5 the IQR. Data points which are beyond 1.5 times the IQR are represented with circles.
} 
Figure 6: Boxplots of F1 values for French (white) and Spanish (grey) vowels produced by male speakers.

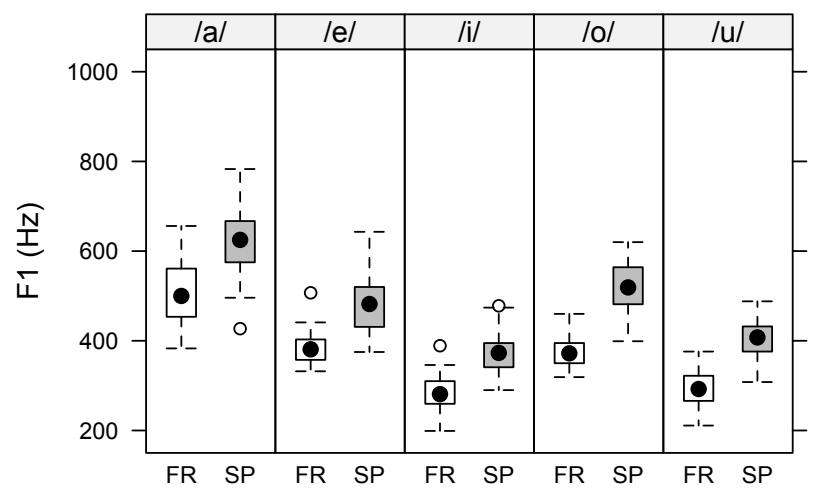

\section{Discussion and conclusion}

The present study has revealed significant differences between French and Spanish in the realization of intervocalic voiceless stops and vowels surrounded by voiceless stops. In intervocalic position, Spanish voiceless stops tend to have shorter stop closures, display incomplete closures more often, and exhibit more voicing than French voiceless stops. In Spanish, two major characteristics of voiceless stops according to standard phonetic descriptions (oral occlusion and absence of glottal vibration) are often compromised in intervocalic position: a quarter of the examined stops lacked a complete closure (i.e. were realized as approximants), and if stops with complete and incomplete closures are taken together, practically half of the examined Spanish stops are voiced throughout their entire closure. These reduction phenomena were also found in French voiceless stops, but to a much lesser extent. Regarding vowels, we found more cases of complete devoicing and greater degrees of partial devoicing in French than in Spanish, in spite of the fact that French vowels were generally longer than their Spanish counterparts. We also found that vowels tend to have significantly lower F1 values in French than in Spanish, suggesting that, at least in the context of stop consonants, French vowels are generally produced with a more constricted vocal tract than Spanish vowels. 
In general, accent appeared to affect French and Spanish voiceless stops and vowels in the same way. In both languages, incomplete closures are rarer in accented than in unaccented stops. Similarly, for both languages stop closures tend to be longer and intensity velocity maxima during CV transitions tend to be higher in accented than in unaccented syllables. These results are in agreement with numerous studies showing that consonants in accented syllables tend to be realized with greater articulatory effort and enhanced acoustic cues (Beckman and Edwards, 1994; Cho and McQueen, 2005; Cole et al., 2007; Keating, 2006, among many others). Finally, in both languages unaccented vowels tended to have lower F1 values than accented vowels, in agreement with the findings of Lindblom (1963) for Swedish. Thus, vowel reduction in the examined context, did not result in centralization, but rather into less open articulations. The fact that accent had a roughly similar effect for French and Spanish vowels and stops indicates that the direction of the examined reduction processes is not essentially different within each segment type and language.

Position in the word appeared to affect voiceless stops more consistently in French than in Spanish. An effect of position in the word on maximum intensity velocities was found for both languages, but only French voiceless stops tended to be longer and maintain a full closure more often in wordinitial than in word-medial position. This may be attributed to the different prosodic systems of these two languages. Since French lacks lexical stress, speakers of this language may opt to mark word boundaries with strengthened articulation in order to facilitate word segmentation for hearers. Spanish speakers, on the other hand, might tend to focus articulatory effort on segments in lexically stressed syllables, since strengthening word-initial unstressed syllables might wrongly signal a stressed syllable and compromise word recognition. Further research would be needed to test this hypothesis.

A particular aspect of the sequences of voiceless stops and vowels analyzed in this study is that they involve antagonistic articulatory gestures at the supraglottal and glottal levels. While voiceless stops require an absence of glottal vibrations and a maximally constricted vocal tract, vowels require the production of voicing and an unconstricted vocal tract. In continuous speech, supraglottal and glottal gestures in these sequences must be blended in some way, and crosslinguistic differences in the "blending strength" (Fowler and Saltzman, 1993) of each of these gestures could appear. Interestingly, our data are consistent with the hypothesis that French and Spanish speakers use asymmetrical coarticulatory strategies when confronted with these seg- 
mental sequences. The degree of constriction and voicing specifications of voiceless stops are generally realized faithfully in French, but French vowels are characterized by low F1 values and often become devoiced. On the other hand, Spanish voiceless stops appear to be greatly coarticulated to adjacent vowels in terms of degree of constriction and voicing. We may hypothesize then that, in terms of constriction degree and voicing, voiceless stops have a higher degree of coarticulatory resistance in French than in Spanish, and, conversely, that vowels have a higher degree of coarticulatory resistance in Spanish than in French.

We can also try to explain our findings by invoking general differences in base of articulation (Honikman, 1964; Disner, 1983; Bradlow, 1995) or specific differences in the phonetic targets and dynamics of stops and vowels in French and Spanish. French vowels and stops might all be characterized by more constricted articulatory targets than Spanish vowels and stops, regardless of the context and the speech register in which they are produced. In support of this hypothesis, Meunier et al. (2003) found that vowels spoken in isolated syllables (e.g. /si/, /mi/, /li/) tended to have lower F1 in French than in Spanish and English. In an older study, however, Delattre (1969) did not find significant differences in F1 between the Spanish and French vowel space. The results of both of these studies, however, should be considered with caution, since they used a small number of speakers.

As for voiceless stops, no explicit comparison of careful speech between French and Spanish has been performed to our knowledge. Nevertheless, it can be noted that the distributions of velocity maxima in CV transitions shown in Figure 4 suggest that, at least at the acoustic level, an important proportion of Spanish stops are similar to their French counterparts. It should be also noted that an explanation entirely based on interlanguage differences in the specification of consonantal constriction degree and vowel openness leaves unanswered our findings regarding the realization of voicing in phonologically voiceless stops. While the extremely constricted nature of French high vowels might plausibly contribute to their frequent devoicing for aerodynamic reasons, the observed interlanguage differences in the occurrence of voicing in phonologically voiceless stops can only be explained by also positing differences in the size of glottal devoicing gestures. For all these reasons, further research is needed to assess the extent to which language-specific bases of articulation or phonetic targets can explain our observations.

In summary, our findings indicate that the extent of reduction that a 
given segment type can undergo in conversational speech can vary significantly across languages, even in the case of two related languages such as French and Spanish. In terms of constriction degree and voicing, Spanish intervocalic voiceless stops appear to be assimilated to adjacent vowels in a greater degree than French voiceless stops. On the other hand, French vowels show more signs of coarticulatory influence from neighboring voiceless stops than Spanish vowels. Based on these observations, we propose that asymmetrical reduction patterns may result from the fact that the supraglottal and glottal gestures of voiceless stops and vowels are attributed different degrees of coarticulatory resistance in each language. Language differences in general "basis-of-articulation" properties or in the exact specification of phonetic targets for voiceless stops and vowels also need to be considered as possible causes of the observed differences in reduction patterns.

\section{References}

Bates, Douglas \& Deepayan Sarkar (2006). lme4: Linear mixed-effects models using S4 classes. URL: http://CRAN.R-project.org, R package version 0.9975-10.

Beckman, Mary \& Jan Edwards (1994). Articulatory evidence for differentiating stress categories. In Keating, Patricia A., editor, Phonological Structure and Phonetic Form: Papers in Laboratory Phonology III, 7-33. Cambridge University Press.

Beddor, Patrice S., James D. Harnsberger \& Stephanie Lindemann (2002). Language-specific patterns of vowel-to-vowel coarticulation: acoustic structures and their perceptual correlates. Journal of Phonetics 30(4). 591-627.

Boersma, Paul (1993). Accurate short-term analysis of the fundamental frequency and the harmonics-to-noise ratio of a sampled sound. In Proceedings of the Institute of Phonetic Sciences, volume 17, 97-110.

Boersma, Paul \& David Weenink (2009). Praat: doing phonetics by computer (Version 5.1.18) [Computer program]. Retrieved October 9, 2009, from http://www.praat.org/. 
Boyce, Suzanne E. (1990). Coarticulatory organization for lip rounding in Turkish and English. Journal of the Acoustical Society of America 88(6). 2584-2595.

Bradlow, Ann R. (1995). A comparative acoustic study of English and Spanish vowels. Journal of the Acoustical Society of America 97(3). 1916-1924.

Browman, Catherine P. \& Louis Goldstein (1990). Tiers in Articulatory Phonology, with some implications for casual speech. In Kingston, John \& Mary Beckman, editors, Papers in Laboratory Phonology 1: between the grammar and the physics of speech, 341-376. Cambridge University Press, Cambridge.

Cho, Taehong \& Peter Ladefoged (1999). Variation and universals in VOT: evidence from 18 languages. Journal of Phonetics 27(2). 207-229.

Cho, Taehong \& James McQueen (2005). Prosodic influences on consonant production in Dutch: Effects of prosodic boundaries, phrasal accent and lexical stress. Journal of Phonetics, 33(2). 121-157.

Cole, Jennifer, Heejin Kim, Hansook Choi \& Mark Hasegawa-Johnson (2007). Prosodic effects on acoustic cues to stop voicing and place of articulation: Evidence from radio news speech. Journal of Phonetics 35(2). 180-209.

Coveney, Aidan (2001). The Sounds of Contemporary French. Exeter: Elm Bank Publications.

Davidson, Lisa (2006). Schwa elision in fast speech: Segmental deletion or gestural overlap? Phonetica 63. 79-112.

Delattre, Pierre (1969). An acoustic study of vowel reduction in four languages. International Review of Applied Linguistics 7(4). 295-325.

Di Cristo, Albert (1999). Vers une modélisation de l'accentuation du français: première partie. French Language Studies 9. 143-179.

Disner, Sandra F. (1983). Vowel quality: The relation between universal and language-specific factors. UCLA Working Papers in Phonetics 58. 
Escudero, Paola, Paul Boersma \& Andréia S. Rauber \& Ricardo A. H. Bion (2009). A cross-dialect acoustic description of vowels: Brazilian and European Portuguese. Journal of the Acoustical Society of America 126(3). 1379-1393.

Fagyal, Zsuzsanna \& Christine Moisset (1999). Sound change and articulatory release: where and why are high vowels devoiced in Parisian French. In Proc. of the 14th ICPhS, 309-312, San Francisco.

Fagyal, Zsuzsanna, Douglas Kibbee \& Fred Jenkins (2006). French: a Linguistic Introduction. Cambridge University Press.

Fowler, Carol and Elliot Saltzman (1993). Coordination and coarticulation in speech production. Language and Speech 36(2,3). 171-195.

Fougeron, Cécile and Caroline Smith (1993). Illustration of the IPA: French. Journal of the International Phonetic Association 23(2). 73-76.

Galliano, Sylvain, Edouard Geoffrois, Djamel Mostefa, Khalid Choukri, JeanFrançois Bonastre \& Guillaume Gravier (2005). ESTER Phase II Evaluation Campaign for the Rich Transcription of French Broadcast Newshase II Evaluation Campaign for the Rich Transcription of French Broadcast News. Proc. Interspeech 2005, 2453-2456.

Honikman, Beatrice (1964). Articulatory settings. In Abercrombie, David, editor, In Honour of Daniel Jones, 73-84. London: Longmans.

Hualde, José I. (2005). The Sounds of Spanish. Cambridge University Press.

Hualde, José I., Miquel Simonet \& Marianna Nadeu (submitted). Consonant lenition and phonological recategorization.

Johnson, Keith (2004). Massive reduction in conversational American English. In Yoneyama, Kiyoko \& Kikuchi Maekawa, editors, Spontaneous Speech: Data and Analysis. Proceedings of the 1st Session of the 10th International Symposium, 29-54, Tokyo, Japan. The National International Institute for Japanese Language.

Jun, Sun-Ah \& Cécile Fougeron (2002). Realizations of accentual phrase in French. Probus 14(1). 147-172. 
Keating, Patricia A. (2006). Phonetic encoding of prosodic structure. In Harrington, Jonathan \& MarijaTabain, editors, Speech production: Models, phonetic processes, and techniques, Macquarie Monographs in Cognitive Science, 167-186. New York and Hove: Psychology Press.

Koopmans-van Beinum, Florina J. (1985). Vowel Contrast Reduction, An acoustic and Perceptual study of Dutch Vowels in Various Speech Conditions. PhD thesis, University of Amsterdam.

Lewis, Anthony (2001). Weakening of Intervocalic /p, t, k/ in Two Spanish Dialects: Toward the Quantification of Lenition Processes. PhD thesis, University of Illinois at Urbana-Champaign.

Lindblom, Björn (1963). Spectrographic study of vowel reduction. The Journal of the Acoustical Society of America 35(11). 1773-1781.

Lindblom, Björn (1990). Explaining phonetic variation: a sketch of the $\mathrm{H} \& \mathrm{H}$ theory. In Hardcastle, William J. \& Alain Marchal, editors, Speech Production and Speech Modelling. Dordrecht: Kluwer Academic Publishers.

Machuca Ayuso, María J. (1997). Las obstruyentes no continuas del español: relación entre las categorías fonéticas y fonológicas en habla esponánea. $\mathrm{PhD}$ thesis, Universitat Autònoma de Barcelona.

Manuel, Sharon (1990). The role of contrast in limiting vowel-to-vowel coarticulation in different languages. Journal of the Acoustical Society of America 88(3). 1286-1298.

Manuel, Sharon (1999). Cross-language studies: Relating language-particular coarticulation patterns to other language-particular facts. In Hardcastle, William J. and Nigel Hewlett, editors, Coarticulation: Theory, Data and Techniques, 179-98. Cambridge University Press.

Martin, Pierre (2004). Dévoisement vocalique en français. La Linguistique 40(2). 3-22.

Meunier, Christine, Chery Frenck-Mestre, Taïssia Lelekov-Boissard \& Martine Le Besnerais (2003). Production and perception of vowels: does the density of the system play a role? In Proceedings of the 15th International Congress of Phonetic Sciences, Barcelona, Spain, 723-726. 
Meunier, Christine, Yvan Meynadier \& Robert Espesser (2008). Voyelles brèves en parole conversationnelle. In Actes, Journées d'Etude sur la Parole 2008, 97-100.

Moon, Seung-Jae \& Björn Lindblom (1994). Interaction between duration, context, and speaking style in English stressed vowels. Journal of the Acoustical Society of America 96(1). 40-55.

Navarro Tomás, Tomás (1977). Manual de pronunciación española. Madrid: Publicaciones de la Revista de Fililogía Española. Consejo Superior de Investigaciones Científicas, 19 edition.

Nguyen, Noël \& Zsuzsanna Fagyal (2008). Acoustic aspects of vowel harmony in French. Journal of Phonetics 36(1). 1-27.

Oftedal, Magne (1985). Lenition in Celtic and in Insular Spanish: the secondary voicing of stops in Gran Canaria. Oslo University Press.

Ohala, John J. \& Carol J. Riordan (1979). Passive vocal tract enlargement during voiced stops. In Wolf, Jared J. and Dennis H. Klatt, editors, Speech communication papers, 89 - 92. Acoust. Soc. of Am.

Öhman, Sven E. G. (1966). Coarticulation in VCV utterances: Spectrographic measurements. Journal of the Acoustical Society of America 39. $151-168$.

Prieto, Pilar \& Marta Ortega-Llebaria (2006). Stress and accent in Catalan and Spanish: Patterns of duration, vowel quality, overall intensity, and spectral balance. In Proceedings of Speech Prosody 2006, Dresden.

Quilis, Antonio \& Matilde Graell (1992). La lengua española en Panamá. Revista de Filología Española 72(3-4). 583-638.

R Development Core Team (2008). R: A Language and Environment for Statistical Computing. R Foundation for Statistical Computing, http://www.R-project.org.

Recasens, Daniel \& Aina Espinosa (2009). Acoustics and perception of velar softening for unaspirated stops. Journal of Phonetics 37(2). 189-211.

Rossi, Mario (1999). L'intonation: le système du français. Gap: Orpheus. 
Ruiz Hernández, J. Vitelio (1984). El consonantismo en Cuba. Havana: Editorial de Ciencias Sociales.

Salvador, Gregorio (1968). Neutralización de G-/K- en español. In C.S.I.C., editor, Actas del XI Congreso Internacional de Lingüistica y Filología Romaánicas, Madrid.

Deepayan Sarkar (2008). Lattice: Multivariate Data Visualization with $R$. Springer.

Smith, Caroline L. (2003). Vowel devoicing in contemporary French. Journal of French Language Studies 13(2). 177-194.

Solé, María-J. (1995). Spatio-temporal patterns of velopharyngeal action in phonetic and phonological nasalization. Language and Speech 38(1). 1-23.

Stetson, Raymond H. (1951). Motor Phonetics. Amsterdam: North-Holland.

Torreblanca, Máximo. (1976). La sonorización de las oclusivas sordas en el habla toledana. Boletín de la Real academia Española de la Lengua 56. $117-146$.

Torreira, Francisco, Martine Adda-Decker \& Mirjam Ernestus (2010). The Nijmegen Corpus of Casual French. Speech Communication 52(3). 201221.

Torreira, Francisco \& Mirjam Ernestus (2010a). The Nijmegen Corpus of Casual Spanish. In Calzolari, Nicoletta, Khalid Choukri, Bente Maegaard, Joseph Mariani, Jan Odijk, Stelios Piperidis, Mike Rosner \& Daniel Tapias, editors, Proceedings of the Seventh conference on International Language Resources and Evaluation (LREC'10), Valletta, Malta. European Language Resources Association (ELRA).

Torreira, Francisco \& Mirjam Ernestus (2010b). Phrase-medial vowel devoicing in spontaneous French. In Proceedings of the 11th Annual Conference of the International Speech Communication Association (Interspeech 2010), pages 2006-2009, Makuhari, Japan.

Tranel, Bernard (1987). The Sounds of French. Cambridge University Press.

Trujillo, Ramón (1970). Resultado de dos encuestas dialectales en Masca. Instituto de Estudios Canarios, La Laguna, Spain. 
Turk, Alice, Nakai Satsuki \& Mariko Sugahara (2006). Acoustic segment durations in prosodic research: A practical guide. In Stefan Sudhoff, editor, Methods in Empirical Prosody Research. Mouton De Gruyter.

van Son, Rob \& Louis Pols (1990). Formant frequencies of Dutch vowels in a text, read at normal and fast rate. Journal of the Acoustical Society of America 88(4). 1683-1693.

van Son, Rob \& Louis Pols (1992). Formant movements of Dutch vowels in a text, read at normal and fast rate. Journal of the Acoustical Society of America 92(1). 121-127.

Warner, Natasha (2005). Reduction of flaps: speech style, phonological environment, and variability. Journal of the Acoustical Society of America 118. 2035-2035. 